\title{
ORGANIZAÇÃO DO TRABALHO DE ENFERMAGEM NA ATENÇÃO BÁSICA: UMA QUESTÃO PARA A SAÚDE DO TRABALHADOR
}

\author{
Helena Maria Scherlowski Leal David ${ }^{1}$, Maria Yvone Chaves Mauro², Viviane Gomes Silva ${ }^{3}$, \\ Michely Alexandrino de Souza Pinheiro ${ }^{4}$,Fernanda Henriques da Silva ${ }^{5}$
}

\footnotetext{
${ }^{1}$ Doutora em Saúde Pública. Professor Adjunto do Departamento de Enfermagem de Saúde Pública da Faculdade de Enfermagem da Universidade do Estado do Rio de Janeiro (UERJ). Rio de Janeiro, Brasil. E-mail: helena.david@uol.com.br

${ }^{2}$ Doutora em Enfermagem. Professor Titular Visitante do Departamento de Enfermagem de Saúde Pública da Faculdade de Enfermagem UERJ. Rio de Janeiro, Brasil. E-mail: mycmauro@uol.com.br

${ }^{3}$ Acadêmica do Curso de Graduação em Enfermagem da Faculdade de Enfermagem da UERJ. Rio de Janeiro, Brasil. E-mail: vivigms@gmail.com

${ }^{4}$ Acadêmica do Curso de Graduação em Enfermagem da Faculdade de Enfermagem da UERJ. Rio de Janeiro, Brasil. E-mail: michelyale@gmail.com

${ }^{5}$ Acadêmica do Curso de Graduação em Enfermagem da Faculdade de Enfermagem da UERJ. Rio de Janeiro, Brasil. E-mail: fehenriques@gmail.com
}

RESUMO: Estudo sobre o impacto da organização do trabalho de enfermeiros, técnicos e auxiliares de enfermagem na Atenção Básica e a sua relação com a saúde destes trabalhadores. Estudo transversal, descritivo e inferencial, com análise bivariada usando o quiquadrado de Pearson. Amostra intencional de 171 profissionais, aplicando-se um questionário fechado com perguntas individuais e um formulário de observação. Escores de insatisfação altos foram obtidos nos itens relação com a chefia (83,6\%), com colegas $(76,3 \%)$, relativo aos horários $(71,9 \%)$ e auto-percepção de pouco controle e oportunidade de decisão sobre o seu trabalho (63,5\%). Associação estatisticamente significativa foi encontrada entre as variáveis clima ruim de trabalho com os companheiros e conflito com clientes ( $p=0,01)$, má organização de turnos e horários $(\mathrm{p}=0,00)$ e ritmo acelerado $(\mathrm{p}=0,00)$. Conclui-se que há necessidade de incluir um olhar específico sobre a organização do trabalho na Atenção Básica, e do apoio de uma política de saúde do trabalhador de enfermagem e saúde.

DESCRITORES: Enfermagem. Condições de trabalho. Riscos ocupacionais. Saúde do trabalhador.

\section{PRIMARY CARE NURSE WORK ORGANIZATION: AN OCCUPATIONAL HEALTH ISSUE}

\begin{abstract}
This is a cross-sectional, descriptive, and inferential study, using Pearson's chi-square test, of the impact of work organization among Primary Care nurses, technicians, and nurses' assistants upon their occupational health. The intentional sample was composed of 171 nursing professionals, using a closed questionnaire with individual questions and an observation form. High dissatisfaction Scores were identified in the items: relationship with leaders (83.6\%), with colleagues $(76.3 \%)$, concerning schedules (71.9\%) and self-perception of low work control and decision-making opportunities (63.5\%). The perception of a poor work environment among colleagues was statistically associated to the variables conflict with customers $(p=0.01)$; bad organization of shifts and schedules $(\mathrm{p}=0.00)$; and accelerated work pace $(\mathrm{p}=0.00)$. We conclude that there is the need to include specific consideration for Primary Care work organization, and support for a worker's health policy in nursing and health care.
\end{abstract}

DESCRIPTORS: Nursing. Working conditions. Occupational risks. Occupational health.

\section{ORGANIZACIÓN DEL TRABAJO DE ENFERMERÍA EN LA ATENCIÓN PRIMARIA: UNA CUESTIÓN PARA LA SALUD LABORAL}

RESUMEN: Estudio sobre el efecto de la organización del trabajo de los enfermeros, técnicos y auxiliares de enfermería que trabajan en la Atención Primaria, y su relación con la salud de esos trabajadores. Estudio transversal, descriptivo e inferencial, con análisis bivariado usando el chi-cuadrado de Pearson. Muestra intencional de 171 profesionales de enfermería, aplicando un cuestionario cerrado con preguntas individuales y de observación. Resultados de elevada insatisfacción fueron identificados en los siguientes temas: relación con los jefes $(83,6 \%)$, con los compañeros $(76,3 \%)$, en relación a los horarios $(71,9 \%)$, y autopercepción de poco control y oportunidad de decisión acerca de su trabajo (63,5\%). Asociación estadísticamente significativa fue encontrada entre las variables ambiente desagradable de trabajo con compañeros y conflicto con clientes $(p=0,01)$, desorganización de turnos y horarios $(p=0,00)$ y ritmo acelerado $(p=0,00)$. Se concluye que hay necesidad de incluir una mirada específica acerca de la organización del trabajo en Atención Primaria, y del apoyo de una política de salud de los trabajadores de enfermería y salud.

DESCRIPTORES: Enfermería. Condiciones de trabajo. Riesgos laborales. Salud laboral. 


\section{INTRODUÇÃO}

A organização do trabalho de enfermagem pode se configurar de modo a afetar negativamente a saúde de quem nela trabalha, sendo objeto de estudo em estreita relação com a saúde do trabalhador. A análise ergonômica do trabalho permite identificar fatores de risco a partir de aspectos organizacionais que, direta ou indiretamente, contribuem para o aumento da carga de trabalho, da exposição a riscos e a condições objetivas e subjetivas inadequadas. O objeto deste artigo é a saúde do trabalhador inserido no nível da Atenção Básica $(\mathrm{AB})$, tomando como base elementos da organização do trabalho, a partir da análise, da percepção dos trabalhadores em um estudo de base ergonômica.

O processo de expansão das estratégias para reorganização da $\mathrm{AB}$ caracteriza a configuração do mercado de trabalho em saúde e enfermagem na década de 90, pari passu com o processo de descentralização administrativa, tornando o nível municipal o grande empregador da força de trabalho em saúde. ${ }^{1}$ Esta rápida expansão se deu no contexto das reformas de estado e da reestruturação produtiva em curso desde as décadas anteriores, determinando alterações nas formas de inserção e emprego e da vida social. Os processos de trabalho vêm passando por mudanças significativas no que se refere às dimensões teórico-conceituais e metodológicas, sem correspondência quanto às condições concretas para a produção das ações de saúde nas unidades e serviços. No que se refere à saúde do trabalhador de enfermagem, desenhase um quadro no qual, aos riscos ocupacionais já conhecidos, somam-se novas questões, referidas aos modos de organizar os processos de trabalho para atender às demandas da população, e aos pressupostos que orientam as políticas de reorganização da $\mathrm{AB}$.

No campo da saúde do trabalhador, a recente publicação pelo Ministério do Trabalho da Norma Regulamentadora 32 (NR-32), evidencia a importância social do trabalho de saúde. Nesta normativa, o lócus de análise e intervenção é mencionado, de modo geral, como Estabelecimentos de Atenção à Saúde (EAS), definidos como “[...] qualquer edificação destinada a prestação de assistência à saúde da população, em qualquer nível de complexidade, em regime de internação ou não", 2:835 incluindo, portanto, o nível da AB. No entanto, a implantação da NR-32 tem sido debatida quase que exclusivamente pelas organizações hospitalares, já que seu conteúdo expressa, em detalhes, aspectos relevantes e objetivos para a segurança e proteção do trabalhador hospitalar, passíveis de submissão a padrões técnicos e operacionais. É ainda incipiente seu alcance em relação às unidades da $\mathrm{AB}$.

$O$ conceito de $A B$ surge e se consolida na década de 90, no contexto de ampliação da descentralização do Sistema Único de Saúde (SUS) e mudança de modelo assistencial, buscando dar destaque às ações de caráter preventivo e de enfrentamento de determinantes de saúde. É fortemente vinculado ao desenvolvimento de mecanismos de repasses financeiros de base per capita aos municípios, em contraposição ao modelo procedimento-centrado, cujas raízes remontam ao antigo Instituto Nacional de Assistência Médica e Previdência Social. O Piso da Assistência Básica e seus incentivos ofereceram condições para a expansão das estratégias prioritárias pelos municípios, condições estas mais simbólicas que financeiras, ressalte-se. Iniciando-se com o Programa de Agentes Comunitários de Saúde (PACS), a ele segue-se o de Saúde da Família (PSF), atualmente denominado Estratégia de Saúde da Família (ESF). ${ }^{3}$

O PACS e o PSF, hoje, se constituem nos grandes empregadores da força de trabalho em enfermagem, sobretudo de enfermeiros. ${ }^{1-4} \mathrm{Nas}$ grandes cidades brasileiras, sua implantação enfrenta um desafio adicional às usuais dificuldades de contratação e perfil de atuação, em função da complexidade da dinâmica da vida nas comunidades e bairros, com seus diversos agenciamentos econômicos e políticos, e pela mobilidade das vagas de trabalho, ao sabor dos investimentos governamentais municipais, determinando intenso fluxo migratório de profissionais entre as cidades, em especial nas áreas metropolitanas ao redor das capitais estaduais. Trata-se um mercado de trabalho em constante flutuação, com diversas possibilidades de trabalho e renda para profissionais de enfermagem, o que pode significar a sobreposição do espaço laboral ao espaço da vida social do trabalhador, e contribuir para o seu adoecimento.

$\mathrm{Na} A B$, as análises com foco na saúde do trabalhador são escassas em comparação com o ambiente hospitalar, exprimindo a persistente dicotomia entre as ações de cunho assistencialcurativas, e as de promoção da saúde e controle de riscos, referidas, respectivamente, ao hospital e às UBs. A partir de um estudo de avaliação da saúde e das condições de trabalho na $\mathrm{AB}$ em dois 
municípios da região Metropolitana do Rio de Janeiro* discute-se o impacto da organização do trabalho de enfermeiros, técnicos e auxiliares de enfermagem inseridos em unidades da $\mathrm{AB}$ sobre sua saúde. Os resultados são debatidos à luz dos referenciais teóricos da abordagem ergonômica, ${ }^{5-6}$ que oferecem ferramentas conceituais e teóricas para a análise de dados sobre condições e modos de organização do trabalho não como constructo teórico, mas como atividade concreta, e da psicodinâmica do trabalho, desenvolvida por Dejours, ${ }^{7-8}$ que inclui os processos de subjetivação do trabalho pelo trabalhador, como elemento para uma compreensão ampliada sobre sua saúde, e as formas como busca enfrentar o sofrimento e o desgaste no trabalho.

\section{MÉTODO}

Trata-se de um estudo quantitativo, transversal, descritivo e inferencial, com amostra intencional de 171 profissionais de enfermagem, distribuídos nas categorias enfermeiro $(n=32)$, técnico de enfermagem $(n=68)$ e auxiliar de enfermagem $(\mathrm{n}=71)$, sendo 96 sujeitos do município de Mesquita e 75 de Nova Iguaçu, região Metropolitana do Rio de Janeiro. Os profissionais atuavam em 39 unidades de $A B$, organizadas em um Centro de Saúde, 34 Postos de Saúde, três Unidades de PACS/PSF e uma Policlínica, que incluía alguns atendimentos de média complexidade em clínicas de especialidades. No grupo, havia 19 sujeitos homens e 152 mulheres.

Nos dois municípios, os critérios de inclusão das unidades foram a pactuação prévia junto aos gestores municipais, coordenadores da $A B$, de saúde do trabalhador e das UBs, e o contato prévio e aquiescência por parte da supervisão/ chefia da unidade para a realização das entrevistas e observação de campo. Todos os trabalhadores de enfermagem destas unidades que estavam ativos no período do estudo foram contactados e convidados a participar da entrevista, realizada no local de trabalho, em dia e horário agendado. Não houve recusas em participar por parte da enfermagem. As visitas para a coleta de dados foram agendadas de modo a contemplar os plantões e horários de serviço distribuídos em todos os dias da semana.
Utilizou-se um instrumento adaptado da Oficina Sindical Européia para a Saúde, previamente validado para aplicação em profissionais de saúde brasileiros..$^{10} \mathrm{O}$ instrumento é composto por três questionários, assim organizados: 1) dados gerais da unidade de saúde, com variáveis sobre o perfil da unidade, numero de trabalhadores por categoria e existência ou não de ações e programas em segurança e saúde do trabalhador; 2) questionário individual de percepção do trabalhador, aplicado por meio de entrevistas face a face, contendo 84 perguntas fechadas sobre as condições ambientais, organizacionais e ergonômicas do trabalho e 3) questionário com 81 perguntas fechadas, preenchido por pesquisador a partir da observação dos ambientes e processos de trabalho, com conteúdo sobre organização, condições ambientais e ergonômicas. Os dados foram coletados entre janeiro de 2006 e abril de 2007.

Na avaliação da organização do trabalho, foram investigadas as seguintes variáveis: percepção quanto à adequação do tempo para execução das tarefas e prazos; aspectos ligados à dimensão cognitiva - oportunidade de desenvolvimento profissional e de educação permanente; aspectos relacionais com os demais colegas, com os clientes e com a chefia; aspectos ergonômicos - repetitividade e ritmo; integração entre os processos dentro da unidade, entre os níveis de atenção $(\mathrm{AB}$, média e alta complexidade) e entre as ações de promoção, prevenção e assistência.

Para cada item foi solicitada uma avaliação, em termos de escore de satisfação: insatisfatório (o profissional considerou o item como não atendido, inadequado ou ruim); satisfatório (quando o item era considerado bom ou razoável, atendendo minimamente às expectativas pessoais) e muito satisfatório (quando o trabalhador expressava sua percepção de que o item contemplava de maneira fortemente positiva suas expectativas ou demandas).

Na perspectiva da ergonomia situada, os estudos da atividade de trabalho consideram a percepção e o conhecimento do trabalhador como elemento imprescindível para avaliar as reais condições em que este trabalho se desenvolve. ${ }^{6}$ Neste processo, ao tempo em que dados relevantes são trazidos para o conhecimento dos pesquisadores e

\footnotetext{
* A pesquisa, intitula-se Avaliação das Condições de Trabalho e Saúde Ocupacional dos Trabalhadores do SUS de Mesquita e Nova Iguaçu, RJ, e integrou a avaliação das dimensões organizativas, ambientais e ergonômicas dos serviços, e de auto-percepção sobre saúde pelos profissionais.
} 
sujeitos, sua discussão permite avançar na compreensão sobre o trabalho e as estratégias coletivas de enfrentamento de problemas e dificuldades. Neste estudo, buscou-se conduzir as entrevistas de modo a favorecer a adesão e confiança do trabalhador para a expressão de sua percepção quanto aos itens dos questionários, pactuando os melhores horários e dias da semana para a coleta de dados.

A análise descritiva e inferencial foi efetuada com apoio do software SPSS, versão 14.0. Os dados foram organizados em freqüências absolutas e relativas, e foi efetuada uma análise bivariada das variáveis utilizando o teste do qui-quadrado de Pearson, destacando-se as que apresentaram associação em nível > 0,05.

O estudo intitulado Avaliação das condições de trabalho e necessidades em saúde ocupacional dos trabalhadores do SUS nos Municípios de Mesquita e Nova Iguaçu, RJ, contou com o apoio da Fundação de Apoio à Pesquisa do Estado do Rio de Janeiro-FAPERJ, por meio do Edital Prioridade Rio 2005. Foi submetido ao Comitê de Ética em Pesquisa com Seres Humanos da Universidade do Estado do Rio de Janeiro, tendo sido aprovado por meio do Protocolo No $1219 / 2005$. Os sujeitos do estudo foram informados e tiveram suas dúvidas esclarecidas verbalmente e por escrito, e sua participação se deu após a assinatura do Termo de Consentimento Livre e Esclarecido.

\section{RESULTADOS E DISCUSSÃO}

Nos municípios estudados, a implantação da ESF é relativamente recente, com menos de cinco anos. Haviam sido implantadas três unidades de Saúde da Família em Mesquita, incluídas no estudo, e Nova Iguaçu estava iniciando sua implantação em áreas que não foram incluídas neste estudo. O modelo de unidades básicas tradicionais, postos e centros de saúde, é o que vinha orientando há décadas a implantação de serviços, prevalecendo um fluxo de atendimento guiado pela demanda espontânea e atendimento por programas (tuberculose, hipertensão, imunizações e outros).

Nesta modalidade de organização de serviços, a hegemonia do modelo procedimento-centrado é evidente, em detrimento da reorganização do processo de trabalho com base nos princípios da clínica ampliada e do trabalho articulado em equipe. ${ }^{9}$ Assim, embora gestores e profissionais explicitassem o desejo e a intencionalidade de efetivar mudanças, via ampliação de cobertura pelo PSF, constata-se a dicotomia entre as dimensões político-ideológicas do trabalho e o mundo das práticas, articulado à esfera das demandas da população, que, nas grandes cidades, e em especial, na região metropolitana do Rio de Janeiro, tende à busca de serviços assistenciais tradicionais para a resolução de problemas já detectados.

Por outro lado, há que considerar as dificuldades para implantação de modelos com base em princípios de territorialização, clientela adscrita e demanda planejada em áreas urbanas de crescimento desordenado, densamente habitadas, mas com intensa mobilidade populacional. Além da complexidade demográfica, a grande extensão territorial, aspectos políticoeconômicos e culturais envolveram a criação de novos municípios na região Metropolitana do Rio de Janeiro durante a década de 90 , como é o caso de Mesquita, um desmembramento de Nova Iguaçu. Trata-se, portanto, de uma reconfiguração político-administrativa recente, que tem impacto importante nas formas de organizar os serviços, e de captar e manter a força de trabalho em saúde. Além disso, precisam dar resposta às demandas da gestão pactuada da regionalização no Estado, sendo que $a B$, por ser de exclusiva responsabilidade municipal, é ainda balizada pelas diversas questões e agenciamentos locais.

Nas UBs dos municípios estudados estão presentes elementos tradicionais da organização e da gestão do trabalho, tais como escalas de horários, divisão do trabalho segundo categoria e prescrição de atividades pré-definidas. O caráter prescritivo da gestão do trabalho impede o desenvolvimento de ações criativas, voltadas para a vigilância da saúde das comunidades e para o estabelecimento de vínculo entre equipes e população, e, na equipe, entre os membros da mesma. Cada categoria profissional segue desenvolvendo suas atividades de modo isolado e não articulado.

A Tabela 1 traz os resultados descritivos, expressos em percentuais, segundo o escore de satisfação proposto. As respostas agrupam as três categorias da enfermagem. 
Tabela 1 - Escore de satisfação dos profissionais de enfermagem sobre a organização do trabalho (n=171). Rio de Janeiro - RJ, 2006-2007

\begin{tabular}{|c|c|c|c|c|}
\hline Item avaliado & Insatisfatório & Satisfatório & Muito bom & Não respondeu \\
\hline & $\%$ & $\%$ & $\%$ & \\
\hline Relação com a chefia & 83,6 & 9,4 & 4,7 & 2,3 \\
\hline Relação com colegas & 76,6 & 14,4 & 4,2 & 1,8 \\
\hline Relação entre conhecimento/formação e trabalho & 74,9 & 10,5 & 7,8 & 4,2 \\
\hline Organização dos turnos/horários & 71,9 & 7,2 & 20,4 & 0,6 \\
\hline Colaboração no trabalho em geral & 69,6 & 15,8 & 9,9 & 4,7 \\
\hline Conciliação entre vida social e trabalho & 69,0 & 17,5 & 11,7 & 1,8 \\
\hline Interesse nas tarefas $\mathrm{x}$ tarefas aborrecidas & 66,1 & 14,0 & 17,0 & 3,9 \\
\hline Grau de controle sobre seu próprio trabalho & 65,5 & 19,9 & 13,5 & 1,2 \\
\hline Oportunidade de decisão & 63,5 & 13.2 & 20,4 & 1,2 \\
\hline Recursos materiais & 61,7 & 18,0 & 20,4 & 2,3 \\
\hline Integração entre os setores de trabalho & 56,7 & 18,1 & 20,5 & 3,5 \\
\hline Relação com clientes & 51,5 & 26,9 & 21,0 & 0,6 \\
\hline Chances de promoção/desenvolvimento & 51,5 & 11,7 & 32,2 & 4,7 \\
\hline $\begin{array}{l}\text { Integração entre ações de promoção, prevenção e recu- } \\
\text { peração da saúde }\end{array}$ & 48,0 & 18,1 & 19,8 & 4,1 \\
\hline Suficiência dos recursos em relação aos prazos & 47,9 & 21,6 & 27,5 & 2,4 \\
\hline Ritmo de trabalho (aceleração) & 47,3 & 25,7 & 26,3 & 0,7 \\
\hline Pressão no trabalho (para a execução) & 47,3 & 25,7 & 26,3 & 0,6 \\
\hline Organização geral do trabalho & 43,3 & 25,7 & 28,1 & 2,3 \\
\hline Existência de equipamento de proteção individual & 41,9 & 19,8 & 35,9 & 1,2 \\
\hline $\begin{array}{l}\text { Integração entre Atenção Básica e alta e média comple- } \\
\text { xidades }\end{array}$ & 35,7 & 26,9 & 31,6 & 5,8 \\
\hline
\end{tabular}

A insatisfação dos profissionais com a chefia $(83,6 \%)$, colegas $(76,3 \%)$, em relação aos horários $(71,9 \%)$ e ritmo de trabalho $(47,3 \%)$ aparecem como itens importantes. A desintegração entre membros de uma equipe e seus processos de trabalho, e a referência a um ambiente permeado de conflitos é relatada em outros estudos sobre equipes de Saúde da Família. ${ }^{11-12}$ Nesses, de modo similar ao presente estudo, configura-se um ambiente de tensão entre membros de uma mesma equipe, ou entre os níveis de gestão, expressando um "embate entre complementaridade e interdependência", 4:440 naturalizado, não explicitado e não enfrentado coletivamente.

Os profissionais se percebem com pouco controle e oportunidade de decisão sobre o seu próprio trabalho $(63,5 \%)$, e expressam pouco interesse pelas tarefas. $\mathrm{Na} A B$, de modo diferente do que ocorre no ambiente hierarquizado do hospital, existem mais condições para que a divisão do trabalho se configure num espaço relevante para a diversidade de atuação da equipe de enfermagem, em especial do enfermeiro, aquecendo discussões importantes sobre as atribuições profissionais, num contexto que privilegia a interdisciplinaridade e o trabalho multiprofissional. A divisão parcelar do trabalho, com fragmentação das tarefas, sob controle da gerência, favorece a perda da noção de totalidade pelo profissional. ${ }^{13}$

A forma de contratação que predomina, nas três categorias, é a de contrato por cooperativa $(55,5 \%)$, em especial entre os enfermeiros (65\%). Seguem-se os contratos com tempo determinado $(17,5 \%)$. Servidores concursados foram observados em maior número entre os auxiliares de enfermagem $(36,6 \%)$, enquanto apenas quatro enfermeiros, dentre os 32 que responderam à pesquisa, eram concursados. Quando perguntados sobre o número de vínculos de trabalho, a maioria (67\%) informou possuir apenas o vínculo de trabalho em questão. Quando se analisa segundo cada categoria profissional, no entanto, existem diferenças - entre os enfermeiros, metade informou ter dois ou mais vínculos de trabalho. 
A contratação por cooperativas é um elemento importante nesta discussão. A expansão desta modalidade de contratação é decorrente do processo de flexibilização do trabalho, no marco das reformas de Estado em curso desde a década de 90 , num contexto de expansão do mercado de trabalho municipal em saúde, e de busca de alternativas para dar conta dos limites impostos pela Lei de Responsabilidade Fiscal para a efetivação dos profissionais como servidores públicos nos municípios. ${ }^{14}$ Embora os princípios do associativismo, ou cooperativismo na saúde, já desde a década de 60 apontem para um processo de autogestão coletiva do trabalho, não é isso o que vem ocorrendo no SUS. Sua função principal é a de terceirizar os serviços, podendo ou não assumir a gestão de unidades de saúde, além de gerenciar o trabalho.

Os processos de inserção voluntária no cooperativismo, com autogestão coletiva e democrática, recomendação expressa amplamente divulgada, inclusive internacionalmente, ${ }^{15}$ se concretiza por meio das assembléias de cooperativados pro forma, convocadas apenas para cumprimento de exigências burocráticas, sem mobilização ou participação efetiva, e sem resultar em ampliação da integração entre os trabalhadores. ${ }^{16}$ Pelo contrário, os processos de trabalho tendem a se dar de modo fragmentado, a partir de interesses de dimensionamento de pessoal cuja decisão é centralizada., ${ }^{4,13}$

O profissional de enfermagem inserido na $\mathrm{AB}$ desenvolve seu trabalho na lógica do cumprimento da carga horária estabelecida, com maior grau de flexibilidade no controle dos profissionais de nível superior. Na busca de ampliar a renda mensal, tendo garantida a possibilidade de acumular vínculos como cooperativado, sua jornada diária de trabalho parece não terminar: de um emprego para o outro, multiplica e acumula a exposição a riscos diversos, sobretudo tendo-se em vista que o pessoal de enfermagem, quando possui mais de um vínculo, tende a lançar mão do horário noturno, por meio de plantões. A flexibilização não avança na direção da proteção do trabalhador, gerando, ao contrário, aumento considerável da insegurança nos projetos de vida. ${ }^{17-19}$ Justifica-se, assim, que estes sujeitos tenham assinalado o item conciliação entre vida social e trabalho como um dos mais insatisfatórios.

Nos serviços analisados, a percepção dos pesquisadores era de que os trabalhadores de enfermagem buscavam cada um, apenas cumprir seu papel, conforme informou uma auxiliar de enfermagem entrevistada. Estudos com equipes de enfermagem inseridas em diversos espaços - assistência, docência e administração trazem a descrição do conceito de burnout como uma síndrome familiar à enfermagem..$^{18}$ A objetificação do outro, colega na equipe, supervisor, chefe ou cliente, define a despersonalização e a falta de envolvimento no trabalho, dimensões presentes nas situações de burnout.

Escassez ou inexistência de recursos materiais foi um item considerado insatisfatório, embora o item - existência de equipamentos de proteção individual tivesse sido avaliado como adequado para mais da metade dos respondentes. A não disponibilidade de equipamentos e insumos necessários para a prática profissional desdobra-se em um conjunto de problemas de ordem objetiva e subjetiva para o trabalhador: desorganização, interrupções constantes do trabalho, exposição a riscos diversos, tanto para a pessoa que está sendo cuidada quanto para o profissional, ansiedade e sensação de trabalho incompleto. ${ }^{19}$

Apesar dos resultados de insatisfação, itens como chance de promoção/desenvolvimento, suficiência dos prazos para a realização das tarefas, ritmo e pressão no trabalho foram avaliados de modo positivo por cerca da metade dos entrevistados, evidenciando diferenças na percepção. $\mathrm{O}$ item relativo às oportunidades de promoção ou desenvolvimento, apontam para a existência de políticas de gestão e educação permanente do trabalho. Quando examinado segundo categoria, no entanto, $46 \%$ dos enfermeiros indicaram o item como satisfatório, contra $77 \%$ dos técnicos de enfermagem e $66 \%$ dos auxiliares. O item - ritmo (aceleração) do trabalho, em todas as categorias, foi apontado como satisfatório ou muito bom por cerca de metade dos respondentes. Este resultado contrasta com a insatisfação de mais da metade dos sujeitos com o item - grau de controle sobre o próprio trabalho, e sugere que este último item não está relacionado com o processo de trabalho em si, mas com sua dimensão decisória.

É, assim, sobretudo a dimensão relacional do trabalho - colegas entre si, e com os níveis hierárquicos - que é percebida como insatisfatória. Durante as entrevistas, era patente o sentimento de não pertencimento às equipes e à unidade de saúde. Um limite do estudo é a não existência de perguntas que busquem identificar explicações ou motivos para os itens percebidos como insatisfatórios.

A análise bivariada corroborou os dados da descritiva. A variável clima ruim com os compa- 
nheiros, apresentou-se estatisticamente associada a - conflito com clientes $(p=0,01)$, má organização de turnos e horários $(p=0,00)$ e ritmo acelerado $(p=0,00)$, indicando a articulação entre as dimensões das relações interpessoais, de tempo e de ritmo do trabalho.

A organização da demanda da população aos serviços de $A B$, nas situações de escassez de oferta de serviços que caracteriza algumas áreas nos municípios estudados, pode se tornar um fato adicional para gerar conflitos entre clientes e profissionais. Numa das unidades estudadas, por exemplo verificou-se que a porta de entrada dividiase em três formas de ingresso do usuário: a primeira, a partir da demanda espontânea, por meio da tradicional "fila da madrugada" para atendimento médico mediante a entrega de fichas; a segunda, se referia aos usuários em tratamento com uso de medicamentos dispensados na unidade, em busca de novas prescrições, sendo usual o agendamento ser feito num prazo além do previsto para a duração dos remédios. Por fim, a entrada também se dava a partir de referências diretas para o médico, de outros médicos da unidade ou de outros serviços. Centralizada na recepção, a porta de entrada se constituía num espaço de conflitos diários, inclusive com relatos de situações de violência sofrida pelos profissionais. Neste caso, é geralmente o auxiliar ou técnico de enfermagem quem atende o usuário que chega, e tenta resolver os impasses para o ingresso no sistema terapêutico. Com uma porta de entrada que na realidade previa três formas de ingresso, a insatisfação era geral, e os processos de trabalho, desintegrados e sobrepostos.

Configura-se um impasse organizacional para cuja resolução seria necessária, a revisão das relações entre profissionais e processos, e a reorganização a partir de prioridades estabelecidas de modo pactuado. A violência no trabalho, que atinge mais freqüentemente os trabalhadores do setor de serviços, ${ }^{20}$ possui origem, neste caso, em um problema da organização do trabalho coletivo. Acredita-se que, nessa situação, os relatos de insatisfação com os colegas, chefia e clientes possuem estreita relação com o episódio descrito.

O episódio evidencia ainda o esgotamento do modelo assistencial centrado na figura do médico e do procedimento assistencial curativo. A enfermagem, neste caso, desenvolve seu trabalho em função das demandas do trabalho médico, que centraliza os demais processos de trabalho em torno das ações de diagnóstico e tratamento de patologias. O nível da $A B$ é, nesta perspectiva, o espaço dos grandes ambulatórios de clínicas, das filas e do atendimento por ordem de chegada, sem considerar necessidades e a estratificação dos riscos.

O item tarefas aborrecidas mostra a percepção de sentimentos de desprazer e monotonia no trabalho. Este item apresentou-se estatisticamente associado a - relação ruim com a chefia $(p=0,00)$, e relação ruim com os clientes $(\mathrm{p}=0,00)$, assinalando a gravidade dos problemas nas relações interpessoais nas equipes.

Chega-se, a partir destes dados, ao tema do sofrimento no trabalho. Sua conceituação não se restringe às situações objetivas de penosidade e carga excessiva de trabalho, já que inclui também os processos de subjetivação, pelo trabalhador, das condições de trabalho e da cultura organizacional naquilo que se configura como impedimento à sua economia psíquica. ${ }^{7}$ A partir da percepção dos sujeitos do estudo, evidencia-se a condição da pressão para trabalhar mal: o trabalhador sabe o que fazer, e tem claros os princípios que devem nortear sua prática, mas o ambiente de trabalho, sobretudo nas suas relações humanas, descaracteriza e torna incompatíveis vontade e ação. ${ }^{8}$

A questão da motivação para o trabalho é outro tema que emerge na reflexão sobre a insatisfação dos trabalhadores de enfermagem. Nas organizações que produzem dentro dos atuais moldes de acumulação flexível de capital, motivação é um conceito que remete a fatores externos que agem sobre o trabalhador, despertando o que, para a cultura da organização parece estar adormecido: a vontade, a decisão, o desejo e o envolvimento com o trabalho. Há uma apropriação equivocada do conceito clássico de alienação, quanto aplicado ao trabalhador considerado desmotivado, entendendo que as causas da desmotivação estão no trabalhador - e não no trabalho. No entanto, para trabalhadores de enfermagem, a organização do trabalho é apontado como o item que mais os desmotiva, seguindo-se as relações interpessoais. O único item não citado como desmotivador, neste caso, é justamente o próprio trabalho. ${ }^{21}$

O prazer que o trabalhador extrai das tarefas que realiza só é possível porque o trabalhador nunca está o tempo todo, nem de modo completo, subsumido às condições do seu trabalho, ainda que adversas. Para enfrentar o sofrimento, no entanto, tece estratégias que podem representar impacto na sua qualidade de vida e saúde. Seu trabalho depende também de sua ação criativa e dos saberes que se produzem a partir da atividade ${ }^{8-9} \mathrm{e}$ o produto de sua ação gera satisfação e prazer. 
Em função desta dualidade prazer-sofrimento que marca a atividade de trabalho, justificam-se as respostas positivas para avaliar o item organização geral do trabalho. Este item, pelo grau de generalização sugerido na sua formulação, induz à avaliação do trabalho em si pelos profissionais de enfermagem, e permite concluir pela valorização do trabalho pelo trabalhador, e pela potencialidade dos saberes da enfermagem para avançar na produção de novas formas de assistir e cuidar na $\mathrm{AB}$.

\section{CONCLUSÕES}

A realização do presente estudo estabeleceu que a desorganização nos processos de trabalho, na avaliação dos trabalhadores de enfermagem, associa-se, de modo especial, às relações entre colegas, chefias e clientes. Tais situações geram conseqüências diretas na saúde dos trabalhadores, evidenciadas na avaliação negativa da compatibilidade entre vida social e profissional, e pode estar intimamente ligada a níveis crescentes de estresse e sofrimento no trabalho.

O processo em curso de mudança na $\mathrm{AB}$ nos dois municípios leva ao questionamento sobre até que ponto problemas organizacionais podem ser enfrentados e modificados com a implantação de estratégias como o PSF, mesmo levando-se em conta as características urbanas e o contexto geral do trabalho. $\mathrm{O}$ fato de não ter sido efetuada uma análise comparativa entre unidades de PSF e unidades implantadas em moldes tradicionais, ao mesmo tempo em que se configura como um limite deste estudo, aponta para novas perguntas de pesquisas sobre o trabalho em saúde e enfermagem.

As questões relativas à força de trabalho em saúde representam um componente crítico para o delineamento de novos paradigmas gerenciais para os serviços de saúde, em especial na área pública. No entanto, nenhuma política de gestão do trabalho se desenvolverá de modo efetivo sem o apoio de uma política de saúde do trabalhador de saúde. Em especial no nível da $A B$, há que reconhecer a dívida sanitária com seus trabalhadores, já que as especificidades do trabalho neste nível são pouco contempladas do ponto de vista normativo e das ações de prevenção e controle. Além da busca do estabelecimento dos fatores determinantes destes problemas de saúde, deve o SUS desenvolver processo de avaliação, prevenção e controle de riscos e danos ocupacionais que atendam as necessidades de saúde do trabalhador dos Centros e Postos de Saúde, Unidades Básicas de Saúde da Família e do PACS.

A reorganização da $\mathrm{AB}$ é o eixo condutor para o reordenamento dos demais níveis de complexidade do sistema de saúde, de forma que se mantenha o compromisso com o acesso da população a todos os níveis de assistência, com a implantação de um novo modelo de gestão que viabilize o suprimento de recursos materiais e um dimensionamento de pessoal que permita organizar o sistema, sem sobrecarga e precarização do trabalho.

Neste sentido pretendeu-se contribuir para o fortalecimento e a defesa do SUS e seu conjunto de ações como uma política pública na qual a garantia de qualidade de vida do trabalho digno para os trabalhadores de saúde seja também uma prioridade.

\section{REFERÊNCIAS}

1. Vieira ALS, Amâncio Filho A, Oliveira ES. Mercado de trabalho em saúde na região sudeste-Brasil: a inserção da equipe de enfermagem. Rev Latino-am Enfermagem. 2004 Jan-Fev; 12(1):134-8.

2. Robazzi MLCC, Marziale MHP. A norma regulamentadora 32 e suas implicações sobre os trabalhadores de enfermagem. Rev Latino-am Enfermagem. 2004 Set-Out; 12(5): 834-6.

3. Levcovitz E, Lima LD, Machado CV. Política de saúde nos anos 90: relações intergovernamentais e o papel das Normas Operacionais Básicas. Ciência Saúde Colet. 2001; 6(2):269-91.

4. Ribeiro EM, Pires D, Blank VL. A teorização sobre processo de trabalho em saúde como instrumental para análise do trabalho no Programa Saúde da Família. Cad Saúde Pública. 2004 Mar-Abr; 20(2):438-46.

5. Brasil. Lei n ${ }^{\circ} 3214$, de 8 de Junho de 1978 - Aprovação das Normas Regulamentadoras da Consolidação das Leis do Trabalho relativas à Segurança e Medicina do Trabalho. Norma Regulamentadora NR17- Estabelece parâmetros para a adaptação das condições de trabalho (ergonomia). Diário Oficial da República Federativa do Brasil, 8 Junho de 1978.

6. Carvão JM, Mauro CCC, Vidal MC, Mauro MYC. A ergonomia no contexto das políticas públicas sobre condições de trabalho: cenários da sua aplicação. Rev Enferm UERJ. 2006 Abr-Jun;14(2):279-85.

7. Dejours C. A banalizaçäo da injustiça social. Rio de Janeiro (RJ): FGV; 2000.

8. Dejours C. O fator humano no trabalho. Rio de Janeiro (RJ): FGV; 2003.

9. Franco T, Peres MAA, Foschiera MMP, Panizzi M. organizadores. Acolher Chapecó: uma experiência 
de mudança do modelo assistencial, com base no processo de trabalho. Chapecó (SC): Prefeitura Municipal, 2004.

10. Mauro MYC, Zeitoune RCG. Metodologia de validação de questionário epidemiológico em ergonomia aplicada a enfermagem com ênfase no estudo da dor lombar. In: Anais do $46^{\circ}$ Congresso Brasileiro de Enfermagem, 1994, Porto Alegre, Brasil. Porto Alegre, 1994.

11. Pedrosa JIS, Teles JBM. Consenso e diferenças em equipes do Programa Saúde da Família. Rev Saúde Pública. 2001 Jun 35(3):303-11.

12. Oliveira EM, Spiri WC. Programa Saúde da Família: a experiência de equipe multiprofissional. Rev Saúde Pública. 2006 Dez-Fev; 40(4):727-33.

13. Matumoto S, Fortuna CM, Mishima SM, Pereira MJB, Domingos NAM. Supervisão de equipes no Programa de Saúde da Família: reflexões acerca do desafio da produção de cuidados. Interface. 2005 Fev; 9(16):9-24.

14. Almeida CMD. Reforma do Estado e reforma de sistemas de saúde: experiências internacionais e tendências de mudança. Ciên Saúde Colet. 1999; 4(2):263-86.

15. Oficina International Del Trabajo (OIT). Labour market. Flexibility - Report of an experts group meeting. Ginebra (SW): OIT; 1986.
16. Teixeira CP. Cooperativas de profissionais de saúde dos serviços municipais e estaduais no município do Rio de Janeiro e a cooperativa do Hospital Geral de Nova Iguaçú: abordando as prestadoras [dissertação]. Rio de Janeiro (RJ): Fundação Oswaldo Cruz. Escola Nacional de Saúde Pública; 2000.

17. Cattani AD, Holzmann L. Dicionário de Trabalho e Tecnologia. Porto Alegre (RS): Editora UFRGS; 2006.

18. Murofuse NT, Abranches SS, Napoleão AA. Reflexões sobre estresse e burnout e a relação com a enfermagem. Rev Latino-am Enfermagem. 2005 Mar-Abr; 13(2):255-61.

19. Marziale MHP, Rodrigues CM. A produção científica sobre os acidentes de trabalho com material perfurocortante entre trabalhadores de enfermagem. Rev Latino-am Enfermagem. 2002 Jul-Ago; 10(4):571-7.

20. David HMSL, Caufield C. Mudando o foco: um estudo exploratório sobre uso de drogas e violência no trabalho entre mulheres das classes populares da cidade do Rio de Janeiro, Brasil. Rev Latino-am Enfermagem. 2005 Nov-Dez; 13(2):1148-54.

21. Pereira MCA, Fávero M. A motivação no trabalho da equipe de enfermagem. Rev Latino-am Enfermagem. 2001 Jul; 9(4):7-12. 